\title{
BMJ Global Health Prevalence, incidence and predictors of volunteer community health worker attrition in Kwale County, Kenya
}

\author{
Anthony K Ngugi, ${ }^{1}$ Lucy W Nyaga, ${ }^{1}$ Amyn Lakhani, ${ }^{1}$ Felix Agoi, ${ }^{1}$ \\ Margrette Hanselman, ${ }^{1}$ George Lugogo, ${ }^{2}$ Kala M Mehta ${ }^{3}$
}

\begin{abstract}
To cite: Ngugi AK, Nyaga LW, Lakhani A, et al. Prevalence, incidence and predictors of volunteer community health worker attrition in Kwale County, Kenya. BMJ Glob Health 2018;3:e000750. doi:10.1136/ bmjgh-2018-000750
\end{abstract}

Handling editor Valery Ridde

- Additional material is published online only. To view please visit the journal online (http://dx.doi.org/10.1136/ bmjgh-2018-000750).

Received 31 January 2018 Revised 12 June 2018 Accepted 16 June 2018

\section{Check for updates}

(c) Author(s) (or their employer(s)) 2018. Re-use permitted under CC BY-NC. No commercial re-use. See rights and permissions. Published by BMJ.

${ }^{1}$ Centre for Population Health Sciences, Faculty of Health Sciences, Aga Khan University (EA), Nairobi, Kenya

${ }^{2}$ Lungalunga Sub-county Public Health Office, Lungalunga Subcounty, Kwale County, Kenya ${ }^{3}$ Department of Epidemiology and Biostatistics, University of California San Francisco, San Francisco, California, USA

Correspondence to Dr Anthony K Ngugi; anthony.ngugi@aku.edu

\section{ABSTRACT}

Introduction In underserved populations, the contribution of community health workers (CHWs) is vital to the healthcare systems. Attrition of these workers causes critical breakdowns in the delivery of essential services to these populations. Literature on reasons for attrition is limited, although some have been identified in studies on sustainability of $\mathrm{CHW}$ programmes. These factors are, however, likely to be influenced by context. We measured $\mathrm{CHW}$ attrition and its predictors in a rural area in Kenya. Methods We conducted a nested case-control study and focus group discussions among CHWs involved in a maternal and child health project. A training register of 1005 CHWs was used to sample and follow CHWs for attrition. Incidence of $\mathrm{CHW}$ attrition was calculated using a Poisson model. Separately, we used logistic regression to determine predictors of $\mathrm{CHW}$ attrition.

Results Of the 1005 CHWs, 498 (49.6\%) had left the project by the time of the study. The incidence of attrition was $46.8 / 1000$ person-years $(95 \% \mathrm{Cl} 38.7$ to 56.5$)$. In the case-control study, lack of interest in peer organisation membership (0R 5.3; 95\% $\mathrm{Cl} 1.3$ to 20.6) was associated with attrition. Absence of refresher training (OR 4.0;95\% Cl 2.2 to 7.1 ) and receiving no feedback from supervisors (OR $2.0 ; 95 \% \mathrm{Cl} 1.0$ to 3.9 ) were also associated with attrition. Discordance in expectations and perceived heavy workload were also identified as key reasons for attrition in the qualitative study.

Conclusion This study estimates high prevalence and incidence of CHW attrition in Kwale County, Kenya. Ongoing training, feedback and peer support are also important in enhancing retention of CHWs. Additionally, expectations regarding the roles and benefits of involvement in $\mathrm{CHW}$ work should be communicated clearly, and workload should be kept reasonable or negotiated with the CHWs.

\section{INTRODUCTION}

Shortage of skilled health workers in underserved areas is a key aspect of the growing human resource crisis in most low-income and middle-income countries. ${ }^{1}$ In order to achieve the Sustainable Development Goals, there is increasing recognition that addressing the health needs of populations requires more sustainable and responsive skills mix that harnesses the potential of community health

\section{Key questions}

What is already known?

- Attrition of community health workers (CHWs) is an important aspect of sustainability of community health work programmes, but the attrition rates and associated factors are unknown in many settings.

What are the new findings?

- At individual level, unclear expectations and heavy workload are important predictors of attrition from CHW programmes.

- Programme management factors such as refresher training, supportive supervision, feedback and peer support are critical determinants of attrition.

What do the new findings imply?

- To enhance the retention of CHWs, clear communication of expectations, reasonable or negotiated workload, ongoing training, supervision and feedback should be considered in the design and implementation of community health programmes.

workers (CHWs) in interprofessional primary care teams. ${ }^{2}$ Recent studies have demonstrated that CHWs can help reduce morbidity and mortality ${ }^{3}{ }^{4}$ and lead to health gains by promoting equitable access to promotive, preventive and curative health services including from maternal, neonatal and child health, ${ }^{5-8}$ infectious diseases ${ }^{9}$ such as HIV/ AIDS $^{10}$ and non-communicable diseases. ${ }^{11-14}$

Reviews of CHW experiences suggest that under the right conditions, scaled up CHW programmes are feasible and can produce wider social benefits over sustained periods of time. ${ }^{15}$ Modelling studies in Kenya showed that scaling up community and primary care interventions to $90 \%$ coverage by 2030 would account for $70 \%$ of all neonatal and under- 5 deaths averted in the two poorest quintiles. ${ }^{16}$

In Kenya, the CHW programme was established in 2006 as a key innovation of the Community Health Strategy, a strategic response of the Kenyan government to the 
reversal in population health gains in the preceding decade. Within this strategy, the CHWs function at the lowest level (tier 1) of service delivery structure known as the Community Health Units $(\mathrm{CHUs})^{\mathrm{i}}$. Within this structure, the CHWs provide promotive and preventive health services at household level. They also collect household-level demographic and health information and assist sick residents to navigate the health system through facilitation of referrals, including following up those under long-term treatment within the community. ${ }^{17}$

However, several factors threaten the sustainability of CHW programmes. CHWs face challenges related to stability in their roles, recognition by and integration into the health system, models of engagement (volunteer vs remunerated workers) and relationships with other health professionals. ${ }^{15}$ Other challenges include inadequate training and supervision and logistical support for supplies. ${ }^{4}$

In most developing countries, CHWs are selected from and serve in deprived socioeconomic settings. They possess low to moderate education, are often women, and work with little or no compensation. ${ }^{18-20}$ Further, CHWs derive their livelihood from the informal economy, which is unstable and provides meagre and inconsistent incomes. Consequently, attrition among this cadre is high, resulting in increased need to constantly recruit and train new workers. This leads to gaps in delivery of services, loss of opportunity to build on experience and increased transactional costs associated with recruitment and training. ${ }^{21}$

Retention of CHWs is a key aspect of sustainability of CHW programmes. Despite the ongoing debate on the topic, retention rates and associated factors are not well documented. ${ }^{22}{ }^{23}$ Published studies present significantly varied estimates of retention, ranging between $23 \%$ and $97 \% .^{23}$ Currently, there is emphasis on improving working conditions and incentives for CHWs as well as calls for context-specific data on their practice environments. $^{2}$

Attrition among health workers is a relatively understudied but important topic. ${ }^{25}{ }^{26}$ Community health programmes have reported that CHW resignations, relocations and reassignments are rampant, leaving the few left behind overburdened and overwhelmed. ${ }^{27}$ Attrition is attributable to life events, discordance in expectations and the absence of adequate monitoring and supervision. Inability to carry out their private work together with voluntary work, disrespect by community members as well as old age are often cited as causes. There is an urgent need to systematically elucidate factors that influence attrition of CHWs, knowledge of which can be

\footnotetext{
${ }^{i}$ Under the Kenya government's Community Health Strategy, the Community Health Unit (CHU) is the lowest level of service delivery, which comprises on average 1000 households (approximately 5000 to 10000 local population), usually within an administratively and geographically defined area and linked to a level 2 (dispensary) or 3 (health centre) healthcare facility.
}

integrated into design of community health programmes to promote sustainability. ${ }^{28}$

As part of a programme to strengthen community and facility-level maternal, neonatal and child health services, we conducted a nested study to estimate the incidence of CHW attrition and explore the associated CHW-level and programme management factors.

\section{METHODS \\ Study setting and study population}

This study was conducted in Matuga, Kinango and Msambweni Sub-counties of Kwale County in the south coast of Kenya. This site was chosen because the Aga Khan University had an ongoing maternal and child health project (Mama na Mtoto (MNM) project) that engaged volunteer CHWs between 2009 and 2015. The target population included 1005 CHWs working in 12 CHUs under the jurisdiction of 10 health facilities serving a catchment population of approximately 150000 people. The community members gathered in community meetings facilitated by the village leadership, local government administration and ministry of health officials, and the project personnel selected the CHWs. The CHWs then received an initial 1-week training on their core responsibilities in the community using the CHW training manual, ${ }^{29}$ which included Concepts of Health and Development, Initiating Community-Based Kenya Essential Packages of Health, Health Promotion and Mother and Child Health among others. After enrolment, the CHWs received more focused training sessions on specific health topics, for example, malaria control and community nutrition, on a regular basis. In this study, we defined a community health worker as 'a member of, selected by, and answerable to the communities where s/he works; supported by the healthcare system; and someone who received less training than the mainstream healthcare workers such as midwives, nurses and clinical officers'. ${ }^{18}$

The 1005 CHWs were trained in the MNM project implemented in the three Sub-counties. ${ }^{30}$ In other counties, similar programmes have increased skilled birth attendance ${ }^{31}$ and the use of Motherpacks. ${ }^{32}$ Their work entailed making home visits during their own free time, with at least one visit per month to each household under their care and more regularly if there was a sick child, a newborn and so on. They provided services that included health education, health promotion activities, for example, building of latrines, installation of hand washing facilities and distribution of mosquito nets, collecting household-level demographic and health information. They also assisted sick residents as they navigated the health system through referrals and tracing/ follow-up of those under long-term treatment within the community. The CHW:population ratio was approximately 1:150.

These were volunteer CHWs and only received a lunch allowance and transport reimbursement whenever they 
attended a meeting or a training session organised by the project team.

A register of the trained CHWs was used to identify the active CHWs (controls) and those who left the CHW programme (drop-out) using specific definitions.

CHWs drop-out is defined in literature as those CHWs who are not fulfilling their duties at time of recording. ${ }^{2633}$ Thus, for this study, the definition of a drop-out CHW was one who by the time of the study had (1) missed three consecutive CHW monthly meetings, had (2) failed to report to a community health extension worker (CHEW) and failed to submit household Community Health Information System (CHIS) data in three consecutive months prior to the study and (3) not participated in and/or relayed reports of other monthly household/villages health promotion activities. Conversely, a retained CHW was one who had satisfactorily achieved the following in the previous 3 months: (1) attend monthly meetings regularly and if missed an apology was shared with the CHUs' office bearers, (2) reported to CHEWs by submitting household monthly CHIS data during the monthly meetings or on agreed dates if missed during the meetings for reasons shared with the officials and (3) participated and relayed reports of other monthly household/ villages health promotion activities.

\section{Study design}

This was a mixed-method study comprising (1) a casecontrol study within a historical cohort of CHWs and (2) a qualitative study composed of two focus groups. The cohort data were used to estimate incidence, and the nested case-control data were used to determine the factors associated with attrition from the CHW programme while the qualitative data were used to add a broader perspective to the quantitative results.

The selection to participate in focus group discussions was done with the help of the village elders and CHW leadership, taking into consideration the villages' representation and the number of CHWs per village (active/ drop-out) to ensure rich, diverse and representative focused discussions.

\section{Study procedures}

At the tail end of the MNM project (November-December 2015), all CHWs trained at the beginning were followed for either attrition or retention. We enlisted the help of the existing CHWs and/or CHEWs as well as used mobile phone contacts to trace subjects lost to follow-up and whose retention status could not be ascertained from the training register to determine their CHW status and when (if) they ceased being active in the CHW programme.

Tracing. The register included demographic information as well as details on date of training/induction into the CHW programme and whether still active. Active CHWs were confirmed by contacting their supervisors (CHEWs) or CHU officials or Community Health Committees (CHCs). CHWs who had dropped out were identified using a similar tracing approach, in addition to further ascertainment of their status from the village elders. Active/drop-out status was further qualified using the definitions given above.

Study questionnaire. Trained enumerators administered the study questionnaire to both active and inactive CHWs (online supplementary appendix 1). The outcome of interest was attrition from the CHW programme and factors of interest included demographic factors, indicators of CHW programme management, specific incentives such as monetary and non-monetary incentives and attitudes towards CHW work including altruism, relationship with the community, health workers' support, community support, decision-making autonomy and CHW selection process.

Two focus group discussions were conducted in Kiswahili among a subset of CHWs from the quantitative study. Six CHWs were included in each focus group: one for active CHWs and another for inactive CHWs. The focus group guide included (1) the process of their selection as a CHW, (2) training, (3) expectations, (4) motivators and barriers to their work and (5) suggestions for improving CHW programmes. Discussion guides (online supplementary appendix 2) were adapted from a BASICS II guide on $\mathrm{CHW}$ incentives and disincentives ${ }^{22}$ and from other questionnaires in literature. ${ }^{3}$

Sample size determination. We estimated that a sample size of 341 and power of $80 \%$ would allow detection of an OR $\geq 2.0$ for any factor with a $\geq 30 \%$ distribution among controls, if sampled at a ratio of 1 case: 2 controls. Participants were selected randomly from the CHW register using the command 'sample' in Stata V.13, with the option 'by (active status)' specifying either active or inactive CHWs. No separate sample size was calculated for the qualitative study.

Data management. The questionnaires for the quantitative and qualitative data were checked and coded before data entry. Data were double entered using a data entry screen in EpiInfo (V.7) and were validated and cleaned in Stata V.13 for quantitative data and in the NVivo for qualitative data.

Data analyses. The distribution of sociodemographic and management characteristics of study participants was presented as proportions comparing CHWs who remained and those who dropped out.

A Poisson model was fitted to calculate the incidence of attrition as the number that dropped out divided by the total person-years of observation. Attrition rates were also estimated for each stratum of demographic and management factors (online supplementary appendix $3 \mathrm{a}, \mathrm{b}$ ).

We used logistic regression to examine the association of CHW and programme management characteristics with attrition. In the bivariate analyses, we examined the association between attrition and 8 demographic and 16 programme management covariates using separate models. Using a stepwise forward selection strategy, covariates that were significant in the bivariate analyses $(p \leq 0.25)$ were included in one multivariate model. Characteristics that were significant $(\alpha=0.05)$ in the multivariate analyses were retained in the final model. 


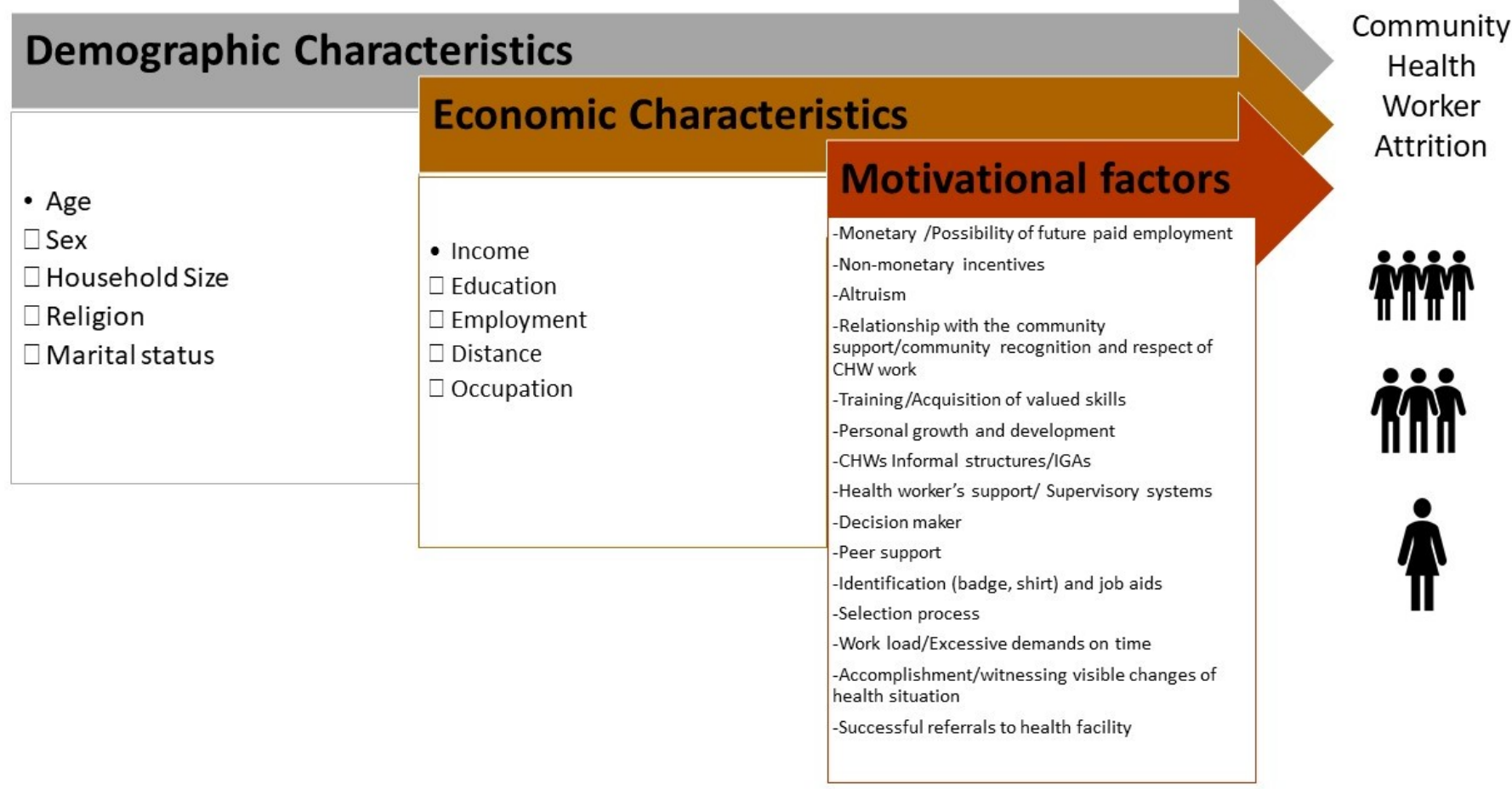

- Age

$\square$ Sex

$\square$ Household Size

$\square$ Religion

$\square$ Marital status

Figure 1 Community health worker (CHW) attrition conceptual framework.

The analysis of qualitative data was guided by the theoretical framework depicted in figure 1 . The qualitative data from the focus group were recorded and transcribed to Microsoft Word. The data were then coded and themes extracted in NVivo. Results from Focus Group Discussions (FGDs) were categorised according to themes from the transcripts of active and inactive CHWs. First, transcripts were used to identify main themes, such as CHW selection procedure, working as CHW, and challenges and recommendations. Thereafter, several subthemes emerged, including selection of CHWs, trainings received, role of a CHW, supervision conducted, support from stakeholders, perceived benefits, motivators for working as a CHW, community perceptions of CHWs, targets and meetings conducted, reasons for CHW continuing being active or inactive, challenges encountered as a CHW and suggestions for improving CHW work. Two raters undertook the process of coding themes. The analysis included theme identification and categorisation. Patterns and connections were also identified within and between categories. Interpretation of themes and connections were balanced with the quantitative findings. Identified themes were compared across the transcripts to determine differences and similarities between the active and inactive CHWs.

\section{RESULTS}

\section{Quantitative results}

Of the 1005 CHWs enrolled in the MNM project, 498 $(49.6 \%)$ dropped out over a 7-year period. A total of 363 CHWs participated in the nested case-control study, which included 111 CHWs who dropped out and 262 who remained in the project.

In the incidence study, the median (IQR) duration of follow-up was 5.7 (3.8-8.1) years. The total person-years of observation (pyo) was 2288.6, including 1801 and 488 pyos for the active and inactive CHW groups, respectively. This yielded an attrition incidence of 46.8/1000 pyo (95\% CI 38.7 to 56.5 ).

Half of the study participants were women and had on average a secondary level of education, and the majority were peasant farmers. Drop-out was higher among male and unmarried CHWs, those employed and/or salaried in non-CHW work (ie, they had another paying job), those younger than 40 years and those with incomes exceeding 6500 Kenya shillings ( US\$65) per month (table 1). Attrition was also higher among CHWs who reported training period $\leq 4$ weeks, being supervised more frequently, infrequent feedback from supervisors and being unclear of the role of a CHW (table 2).

In the bivariate analyses, the majority of the sociodemographic characteristics under consideration were associated with attrition $(\mathrm{p}<0.25)$ (table 3$)$. Frequency of supervision in the previous month, receiving no refresher training, infrequent feedback from supervisor, absence of cash emoluments, reported lack of support at work, poor understanding of CHW roles, performance evaluation, type of perceived constraints to CHW work, perceived lack of need for peer group membership and number of households visited in the previous month were also associated with attrition in the bivariate analyses (table 4 ). 
Table 1 Sociodemographic characteristics in the Community Health Worker Attrition Study, Kwale County, Kenya

\begin{tabular}{|c|c|c|c|}
\hline Characteristic & $\begin{array}{l}\text { Community health workers } \\
\text { who left (\%) } \\
n=112\end{array}$ & $\begin{array}{l}\text { Community health workers } \\
\text { who remained active (\%) } \\
\mathrm{n}=262\end{array}$ & $\begin{array}{l}\text { Total } \\
n=374\end{array}$ \\
\hline \multicolumn{4}{|l|}{ Age group (years) } \\
\hline$\leq 30$ & 34 (39) & $53(60.9)$ & 87 \\
\hline $31-40$ & 39 (31.5) & $85(68.5)$ & 124 \\
\hline$\geq 41$ & 33 (21.2) & $123(78.8)$ & 156 \\
\hline \multicolumn{4}{|l|}{ Sex } \\
\hline Female & $43(38)$ & $139(53)$ & 181 \\
\hline Male & $69(62)$ & $123(47)$ & 193 \\
\hline \multicolumn{4}{|l|}{ Marital status } \\
\hline Single & $12(32)$ & $25(68)$ & 37 \\
\hline Married & $88(29)$ & $221(72)$ & 309 \\
\hline Widowed & $4(27)$ & $11(73)$ & 15 \\
\hline Separated/divorced & 7 (58.3) & $5(4)$ & 12 \\
\hline \multicolumn{4}{|l|}{ Level of education } \\
\hline None/primary incomplete & 23 (31.9) & $49(68.1)$ & 72 \\
\hline $\begin{array}{l}\text { Primary complete/secondary } \\
\text { incomplete }\end{array}$ & $57(26.0)$ & $162(74.0)$ & 219 \\
\hline $\begin{array}{l}\text { Secondary complete/tertiary } \\
\text { incomplete }\end{array}$ & $30(37.0)$ & $51(63.0)$ & 81 \\
\hline \multicolumn{4}{|l|}{ Religion } \\
\hline Christian & $29(23.6)$ & $94(76.4)$ & 123 \\
\hline Muslim & $82(33.3)$ & $164(66.7)$ & 246 \\
\hline \multicolumn{4}{|l|}{ Occupation } \\
\hline None & $12(33.3)$ & $24(66.7)$ & 36 \\
\hline Business/large-scale farmer & $30(28.6)$ & $75(71.4)$ & 105 \\
\hline Employed & $11(61.1)$ & 7 (38.9) & 18 \\
\hline Peasant farmer & $37(22.2)$ & $130(77.8)$ & 167 \\
\hline Casual labour & $12(40.0)$ & $18(60.0)$ & 30 \\
\hline Other employment & 7 (53.9) & $6(46.2)$ & 13 \\
\hline \multicolumn{4}{|l|}{ Source of income } \\
\hline Salaried & $17(68.0)$ & $8(32.0)$ & 25 \\
\hline Farmer & 39 (22.9) & $131(77.1)$ & 170 \\
\hline Self-employed & $33(27.7)$ & $86(72.3)$ & 119 \\
\hline Support by family & $8(34.8)$ & $15(65.2)$ & 23 \\
\hline Others & $9(31.0)$ & $20(69.0)$ & 29 \\
\hline \multicolumn{4}{|l|}{ Monthly income (Kenya shillings) } \\
\hline$\leq 3500$ & $47(24.1)$ & $148(75.9)$ & 195 \\
\hline $3501-6500$ & 27 (32.5) & $56(675)$ & 83 \\
\hline$>6500$ & 36 (40.9) & $52(59.1)$ & 88 \\
\hline
\end{tabular}

In the multivariate analyses, attrition was high among men (OR 2.7; 95\% CI 1.5 to 4.8 ), among separated or divorced CHWs (OR 4.9; $95 \%$ CI 1.3 to 18.8) and among younger CHWs (30 years or less, OR 4.0, 95\% CI 1.9 to 8.4; 31-40 years, OR 2.4, 95\% CI 1.3 to 4.5) (table 3). Attrition was higher among those with no refresher training
(OR 4.0; 95\% CI 2.2 to 7.1), among those who reported receiving no feedback from supervisors (OR 2.0; $95 \%$ CI 1.0 to 3.9 ) and among those who reported that belonging to a peer organisation such as a CHW group was not a motivation (OR 5.3; 95\% CI 1.3 to 20.6). Surprisingly, attrition was lower among CHWs who reported less 
BMJ Global Health

Table 2 Management characteristics in the Community Health Worker Attrition Study, Kwale County, Kenya

\begin{tabular}{|c|c|c|c|}
\hline Characteristic & $\begin{array}{l}\text { Community health workers } \\
\text { who left }(\%) \\
n=112\end{array}$ & $\begin{array}{l}\text { Community health workers } \\
\text { who remained active (\%) } \\
\mathrm{n}=262\end{array}$ & $\begin{array}{l}\text { Total } \\
\mathrm{n}=374\end{array}$ \\
\hline \multicolumn{4}{|l|}{ Trained $>4$ weeks } \\
\hline No & $105(30.5)$ & $239(69.5)$ & 344 \\
\hline Yes & $6(23.1)$ & $20(76.9)$ & 26 \\
\hline \multicolumn{4}{|l|}{ Refresher training $(\leq 1)$} \\
\hline No & $54(51.4)$ & $51(48.6)$ & 105 \\
\hline Yes & $52(19.9)$ & $209(80.1)$ & 261 \\
\hline \multicolumn{4}{|c|}{ Supervision last 1 month } \\
\hline None & $28(26.7)$ & 77 (73.3) & 105 \\
\hline 1 time & $31(21.8)$ & $111(78.2)$ & 142 \\
\hline 2 times & $23(29.5)$ & $55(70.5)$ & 78 \\
\hline 3 times & $14(60.9)$ & $9(39.1)$ & 23 \\
\hline$>3$ times & $15(60.0)$ & $10(39.1)$ & 25 \\
\hline \multicolumn{4}{|l|}{ Supervisor } \\
\hline $\mathrm{CHC}$ members & $38(25.7)$ & $110(74.3)$ & 148 \\
\hline CHEW & $61(30.5)$ & $139(69.5)$ & 200 \\
\hline Others & $8(40.0)$ & $12(60.0)$ & 20 \\
\hline \multicolumn{4}{|c|}{ Feel supervision adequate } \\
\hline No & $42(30.2)$ & $97(69.8)$ & 139 \\
\hline Yes & 67 (29.3) & $162(70.7)$ & 229 \\
\hline \multicolumn{4}{|c|}{ Feedback from supervisor } \\
\hline No & $34(40.0)$ & $51(60.0)$ & 85 \\
\hline Yes & 75 (26.6) & 208 (73.5) & 283 \\
\hline \multicolumn{4}{|c|}{$\begin{array}{l}\text { Adequate support from } \\
\text { supervisor }\end{array}$} \\
\hline No & 37 (31.4) & $81(68.6)$ & 118 \\
\hline Yes & $71(28.3)$ & $180(71.7)$ & 251 \\
\hline \multicolumn{4}{|c|}{ Received cash payments } \\
\hline No & $53(27.0)$ & $143(73.0)$ & 196 \\
\hline Yes & $58(32.8)$ & $119(67.2)$ & 177 \\
\hline \multicolumn{4}{|l|}{ Opinion on $\mathrm{CHWs}$} \\
\hline Volunteer entirely & $50(30.3)$ & $115(69.7)$ & 165 \\
\hline Get salary & 49 (32.9) & $100(67.1)$ & 149 \\
\hline $\begin{array}{l}\text { Get stipend+other } \\
\text { allowances }\end{array}$ & $12(21.8)$ & $43(78.2)$ & 55 \\
\hline \multicolumn{4}{|c|}{ Who should select $\mathrm{CHWs}$} \\
\hline Community & $87(28.7)$ & $216(71.3)$ & 303 \\
\hline $\mathrm{CHC}, \mathrm{MOH}$, etc & $24(34.8)$ & $45(65.2)$ & 69 \\
\hline \multicolumn{4}{|c|}{ Community appreciate work } \\
\hline No & $2(50.0)$ & $2(50.0)$ & 4 \\
\hline Yes & 109 (29.6) & $259(70.4)$ & 368 \\
\hline \multicolumn{4}{|l|}{$\begin{array}{l}\text { Peer association } \\
\text { membership }\end{array}$} \\
\hline No & $12(70.6)$ & $5(29.4)$ & 17 \\
\hline Yes & 99 (27.9) & $256(72.1)$ & 355 \\
\hline
\end{tabular}


Table 2 Continued

\section{Characteristic}

Community health workers Community health workers who left (\%) $\mathrm{n}=\mathbf{1 1 2}$ who remained active (\%) $n=262$

Total
$\mathrm{n}=374$

Receive support to enhance CHW work

\begin{tabular}{|c|c|c|c|}
\hline No & $56(32.6)$ & $116(67.4)$ & 172 \\
\hline Yes & $50(26.2)$ & $141(73.8)$ & 191 \\
\hline \multicolumn{4}{|l|}{ Understand $\mathrm{CHW}$ roles } \\
\hline No & $4(66.7)$ & $2(33.3)$ & 6 \\
\hline Yes & $107(29.2)$ & $260(70.8)$ & 367 \\
\hline \multicolumn{4}{|l|}{ Performance ever evaluated } \\
\hline No & $21(42.0)$ & $29(58.0)$ & 50 \\
\hline Yes & $90(27.9)$ & $233(72.1)$ & 323 \\
\hline \multicolumn{4}{|l|}{ Days worked/month } \\
\hline $0-5$ & $53(26.8)$ & 145 (73.2) & 198 \\
\hline $6-10$ & $32(32.3)$ & $67(67.7)$ & 99 \\
\hline$>10$ & 25 (33.3) & $50(66.7)$ & 75 \\
\hline \multicolumn{4}{|l|}{ Households visited last month } \\
\hline $0-5$ & $15(40.5)$ & $22(59.5)$ & 37 \\
\hline $6-15$ & $34(30.9)$ & $76(69.1)$ & 110 \\
\hline$\geq 16$ & $60(27.0)$ & $162(73.0)$ & 222 \\
\hline \multicolumn{4}{|l|}{ Forum/dialogues last month } \\
\hline None & $23(34.9)$ & $43(65.2)$ & 66 \\
\hline Only 1 & $14(16.7)$ & $70(83.3)$ & 84 \\
\hline $2-4$ & $58(32.8)$ & 119 (67.2) & 117 \\
\hline$\geq 5$ & $16(35.6)$ & $29(64.4)$ & 45 \\
\hline \multicolumn{4}{|l|}{ Clients referred last month } \\
\hline None & $30(31.9)$ & $64(68.1)$ & 94 \\
\hline Only 1 & $10(23.3)$ & $33(76.7)$ & 43 \\
\hline $2-5$ & $47(29.2)$ & $114(70.8)$ & 161 \\
\hline$\geq 6$ & $22(31.9)$ & $47(68.1)$ & 69 \\
\hline \multicolumn{4}{|l|}{ Why became $\mathrm{CHW}$} \\
\hline To assist community & $89(29.0)$ & $218(71.0)$ & 307 \\
\hline Other reasons* & $20(31.8)$ & $43(68.3)$ & 63 \\
\hline \multicolumn{4}{|l|}{ Constraints faced as $\mathrm{CHW}$} \\
\hline Lack of supplies & $15(26.3)$ & $42(73.7)$ & 57 \\
\hline Lack of transport & $27(28.7)$ & $67(71.3)$ & 94 \\
\hline Lack of community support & $29(24.2)$ & $91(75.8)$ & 120 \\
\hline Financial constraints & $32(40.0)$ & $48(60.0)$ & 80 \\
\hline Others & $7(38.9)$ & $11(61.1)$ & 18 \\
\hline
\end{tabular}

*Encouraged by community or family, for recognition in the community, for salary/stipend/tokens and to advance a career in health. $\mathrm{CHC}$, community health committee; $\mathrm{CHEW}$, community health extension worker; $\mathrm{CHW}$, community health worker; $\mathrm{MOH}$, $\mathrm{Ministry}$ of $\mathrm{Health}$.

frequent supervision, with ORs ranging between 4.2 and 9.1 among those not supervised, or supervised one or two times relative to those supervised more than three times in their most current month of service $(\mathrm{p}<0.001)$. Financial incentives were not associated with attrition (table 4).

Qualitative results
Thematic analyses of the qualitative data suggested several key themes: role of a CHW, effect of training, perceived benefits of compensation, social motivators and workload. The initial themes were quite similar between the two groups of CHWs. There was common understanding of what CHW work entailed. Both groups 
Table 3 Demographic factors associated with attrition of community health workers in the Community Health Worker Attrition Study, Kwale County, Kenya

\begin{tabular}{|c|c|c|c|c|}
\hline \multirow[b]{2}{*}{ Factor } & \multicolumn{2}{|l|}{ Univariate analyses } & \multicolumn{2}{|l|}{ Multivariate analyses } \\
\hline & OR (95\% Cl) & P values & OR $(95 \% \mathrm{Cl})$ & $P$ values \\
\hline \multicolumn{5}{|l|}{ Age group (years) } \\
\hline$\geq 41$ & 1 & & 1 & \\
\hline$\leq 30$ & 2.39 (1.34 to 4.26$)$ & & 3.95 (1.86 to 8.42$)$ & \\
\hline $31-40$ & 1.71 (1.00 to 2.93$)$ & 0.01 & 2.36 (1.25 to 4.46$)$ & 0.001 \\
\hline \multicolumn{5}{|l|}{ Sex } \\
\hline Female & 1 & & 1 & \\
\hline Male & 1.86 (1.17 to 2.92$)$ & 0.008 & 2.66 (1.47 to 4.82$)$ & 0.001 \\
\hline \multicolumn{5}{|l|}{ Marital status } \\
\hline Married & 1 & & 1 & \\
\hline Single & 1.20 (0.58 to 2.50$)$ & & $0.56(0.22$ to 1.45$)$ & \\
\hline Widowed & 0.91 (0.28 to 2.94) & & 2.34 (0.66 to 9.00$)$ & \\
\hline Separated/divorced & $3.52(1.09$ to 11.37$)$ & 0.2 & 4.92 (1.29 to 18.82$)$ & 0.04 \\
\hline \multicolumn{5}{|l|}{ Level of education } \\
\hline None/primary incomplete & 1 & & 1 & \\
\hline $\begin{array}{l}\text { Primary complete/secondary } \\
\text { incomplete }\end{array}$ & $0.75(0.42$ to 1.34$)$ & & $0.58(0.30$ to 1.14$)$ & \\
\hline Secondary complete/tertiary & 1.25 (0.64 to 2.45$)$ & 0.16 & $0.72(0.31$ to 1.65$)$ & 0.28 \\
\hline \multicolumn{5}{|l|}{ Religion } \\
\hline Muslim & & 1 & 1 & \\
\hline Christian & & $0.62(0.38-1.01)$ & $0.64(0.35-1.19)$ & 0.16 \\
\hline \multicolumn{5}{|l|}{ Occupation } \\
\hline Peasant farmer & 1 & & 1 & \\
\hline Business/large-scale farmer & $1.41(0.80$ to 2.46$)$ & & $1.43(0.57$ to 3.55$)$ & \\
\hline Employed & $5.52(2.00$ to 15.24$)$ & & 0.56 (0.09 to 3.38$)$ & \\
\hline None & $1.76(0.80$ to 3.84$)$ & & $0.76(0.22$ to 2.62$)$ & \\
\hline Casual labour & 2.34 (1.04 to 5.30$)$ & & $0.38(0.08$ to 1.84$)$ & \\
\hline Others & 4.10 (1.29 to 12.95$)$ & 0.005 & $1.38(0.37$ to 9.11$)$ & 0.45 \\
\hline \multicolumn{5}{|l|}{ Source of income } \\
\hline Farmer & 1 & & 1 & \\
\hline Salaried & 7.12 (2.86 to 17.79$)$ & & $6.22(1.19$ to 32.43$)$ & \\
\hline Self-employed & $1.29(0.75$ to 2.21$)$ & & $0.65(0.26$ to 1.62$)$ & \\
\hline Support by family & $1.79(0.71$ to 4.54$)$ & & $2.56(0.54$ to 12.04$)$ & \\
\hline Others & 1.51 (0.64 to 3.59$)$ & 0.001 & 1.91 (0.49 to 7.40$)$ & 0.06 \\
\hline \multicolumn{5}{|l|}{ Monthly income (Kenyan shillings) } \\
\hline$\leq 3500$ & 1 & & 1 & \\
\hline $3501-6500$ & 1.52 (0.86 to 2.67$)$ & & 1.37 (0.71 to 2.65$)$ & \\
\hline$>6500$ & 2.18 (1.27 to 3.73$)$ & 0.02 & 1.73 (0.91 to 3.33$)$ & 0.23 \\
\hline
\end{tabular}

noted that training was beneficial. For those who dropped out, the perceived benefit of compensation was a more salient feature, while social motivators like their stature or perception in the community seemed to prevail over monetary compensation among those who remained. Both groups noted the increased workload as a demotivating factor. Online supplementary file 1 presents a comparative summary of key themes from the qualitative study.

Role of a CHW. The CHWs understood their duties to include educating the communities on health issues such as maintaining good hygiene and having a toilet. Additionally, they would encourage the people who are sick to seek medical attention, ask pregnant mothers to 
Table 4 Programme management factors associated with attrition of CHWs in the Community Health Worker Attrition Study, Kwale County, Kenya

\begin{tabular}{|c|c|c|c|c|}
\hline \multirow[b]{2}{*}{ Factor } & \multicolumn{2}{|l|}{ Univariate analyses } & \multicolumn{2}{|c|}{ Multivariate analyses } \\
\hline & OR (95\% Cl) & $P$ values & OR $(95 \% \mathrm{Cl})$ & $P$ values \\
\hline \multicolumn{5}{|c|}{ Supervision last 1 month } \\
\hline$>3$ times & 1 & & 1 & \\
\hline None & 0.24 (0.10 to 0.60$)$ & & 0.13 (0.04 to 0.39$)$ & \\
\hline 1 time & 0.17 (0.08 to 0.46$)$ & & 0.17 (0.06 to 0.48$)$ & \\
\hline 2 times & $0.29(0.11$ to 0.71$)$ & & 0.27 (0.09 to 0.83$)$ & \\
\hline 3 times & 1.04 (0.33 to 3.30$)$ & $<0.001$ & 0.95 (0.24 to 3.72) & $<0.001$ \\
\hline \multicolumn{5}{|c|}{ Refresher training $(\leq 1)$} \\
\hline Yes & 1 & & 1 & \\
\hline No & 4.26 (2.61 to 6.94$)$ & $<0.001$ & 3.95 (2.20 to 7.10$)$ & $<0.001$ \\
\hline \multicolumn{5}{|c|}{ Feedback from supervisor } \\
\hline Yes & 1 & & 1 & \\
\hline No & 1.85 (1.11 to 3.07$)$ & 0.02 & 1.99 (1.01 to 3.91$)$ & 0.05 \\
\hline \multicolumn{5}{|c|}{ Received cash payments } \\
\hline Yes & 1 & & 1 & \\
\hline No & $0.76(0.49$ to 1.21$)$ & 0.23 & $0.77(0.44$ to 1.35$)$ & 0.37 \\
\hline
\end{tabular}

Receive support to enhance

CHW work

\begin{tabular}{|c|c|c|c|c|}
\hline Yes & 1 & & 1 & \\
\hline No & $1.36(0.86$ to 2.14$)$ & 0.18 & $1.26(0.71$ to 2.25$)$ & 0.43 \\
\hline \multicolumn{5}{|l|}{ Understand $\mathrm{CHW}$ roles } \\
\hline Yes & 1 & & 1 & \\
\hline No & 4.86 (0.88 to 26.93$)$ & 0.07 & $2.96(0.34$ to 25.50$)$ & 0.32 \\
\hline \multicolumn{5}{|l|}{ Performance ever evaluated } \\
\hline Yes & 1 & & 1 & \\
\hline No & 1.87 (1.02 to 3.46$)$ & 0.04 & 1.75 (0.74 to 4.12$)$ & 0.20 \\
\hline \multicolumn{5}{|l|}{ Constraints faced as $\mathrm{CHW}$} \\
\hline Lack of supplies & 1 & & 1 & \\
\hline Lack of transport & 1.12 (0.54 to 2.36$)$ & & 0.86 (0.33 to 2.21$)$ & \\
\hline Lack of community support & 0.89 (0.43 to 1.84$)$ & & 0.93 (0.38 to 2.31$)$ & \\
\hline Financial constraints & 1.87 (0.89 to 3.91$)$ & & 2.13 (0.84 to 5.37$)$ & \\
\hline Others & 1.37 (0.58 to 5.44$)$ & 0.15 & 1.27 (0.32 to 5.09$)$ & 0.09 \\
\hline \multicolumn{5}{|l|}{$\begin{array}{l}\text { Households visited in the last } \\
\text { month }\end{array}$} \\
\hline$>16$ & 1 & & 1 & \\
\hline $0-5$ & 1.84 (0.89 to 3.78$)$ & & 2.54 (1.07 to 6.02$)$ & \\
\hline $6-16$ & $1.21(0.73$ to 1.99$)$ & 0.23 & 1.44 (0.78 to 2.67$)$ & 0.14 \\
\hline \multicolumn{5}{|l|}{$\begin{array}{l}\text { Peer association } \\
\text { membership }\end{array}$} \\
\hline Yes & 1 & & 1 & \\
\hline No & 6.21 (2.13 to 18.07$)$ & $<0.001$ & 5.26 (1.34 to 20.61$)$ & 0.02 \\
\hline \multicolumn{5}{|l|}{ Supervisor } \\
\hline CHEW & 1 & & & \\
\hline $\mathrm{CHC}$ members & $0.78(0.49$ to 1.27$)$ & & & \\
\hline Others & 1.52 (0.59 to 3.90$)$ & 0.34 & & \\
\hline
\end{tabular}


Table 4 Continued

\begin{tabular}{|c|c|c|c|c|}
\hline \multirow[b]{2}{*}{ Factor } & \multicolumn{2}{|l|}{ Univariate analyses } & \multicolumn{2}{|c|}{ Multivariate analyses } \\
\hline & OR $(95 \% \mathrm{Cl})$ & $P$ values & OR $(95 \% \mathrm{Cl})$ & $P$ values \\
\hline \multicolumn{5}{|l|}{ Feel supervision adequate } \\
\hline Yes & 1 & & & \\
\hline No & 1.05 (0.66 to 1.66$)$ & 0.85 & & \\
\hline \multicolumn{5}{|l|}{ Adequate support from supervisor } \\
\hline Yes & 1 & & & \\
\hline No & $1.15(0.72$ to 1.86$)$ & 0.55 & & \\
\hline \multicolumn{5}{|l|}{ Opinion on $\mathrm{CHWs}$} \\
\hline Volunteer entirely & 1 & & & \\
\hline Get salary & $1.13(0.70$ to 1.81$)$ & & & \\
\hline Get stipend+other allowances & $0.64(0.31$ to 1.32$)$ & 0.31 & & \\
\hline \multicolumn{5}{|l|}{ Who should select CHWs } \\
\hline Community & 1 & & & \\
\hline $\mathrm{CHC}, \mathrm{MOH}$, etc & 1.132 (076 to 2.31$)$ & 0.32 & & \\
\hline \multicolumn{5}{|l|}{ Days worked/month } \\
\hline $0-5$ & 1 & & & \\
\hline $6-10$ & $1.31(0.77$ to 2.21$)$ & & & \\
\hline$>10$ & 1.37 (0.77 to 2.43 ) & 0.45 & & \\
\hline \multicolumn{5}{|l|}{ Why became CHW } \\
\hline To assist community & 1 & & & \\
\hline Other reasons & $1.14(0.63$ to 2.04$)$ & 0.66 & & \\
\hline
\end{tabular}

$\mathrm{CHC}$, community health committee; CHEW, community health extension worker; $\mathrm{CHW}$, community health worker; $\mathrm{MOH}, \mathrm{Ministry}$ of $\mathrm{Health}$.

deliver at health facilities, counsel nursing mothers on exclusive breast feeding and childhood immunisations, identify Tuberculosis (TB) and Anti-retroviral (ARV) medication defaulters, encourage boiling or treatment of (drinking) water, register members of assigned households and conduct monthly household visits to identify health issues.

Supervision for the CHWs. Participants from both groups identified the CHC members as their supervisors. The CHCs would conduct monthly supervision to review their reports and forward their reports to CHEWs if the CHWs lived far from the health facility. Sometimes the CHCs validate their reports by accompanying them during household visits. The CHWs, however, felt that CHCs were often overwhelmed by the task and suggested that the village elder be included to support in some areas.

In terms of improvement on supervision, the participants from the inactive FGD felt that identification cards (given to them) had improved their recognition in the community. The inclusion of the Public Health Officers (PHOs) and CHEWs as part of the supervision team also enhanced their stature as was pointed out by active CHWs. They also advocated for the CHC to receive some token (allowance) for the work they do.

Social motivation. Participants from the active FGD indicated that they were happy when there were no health problems in the community and as such the (community) money that would have been spent seeking treatment was diverted to family needs. Some CHWs were asked for referrals by villagers before they went to the hospital. The CHWs also felt recognised during the trainings they received from Aga Khan University. Incentives, specifically the Khangas (traditional printed linen), t-shirts and identification badges, were identified as useful motivators. They appreciated that the badges differentiated them from the common villagers.

Respondents in the inactive CHW group were demotivated by the fact they were selected without their consent and informed that they would be volunteers without pay. They felt that they owed the community a duty having been selected and did not want to be portrayed as (being) against development if they declined. They took on the work hoping they would be compensated as (was subsequently) promised by their (CHU) chairman. They also thought they would be provided with (means of) transport such as motorcycle or bicycle (but that was not forthcoming).

Both groups reported mixed community views about their work. Some appreciated their work, for example, when they took their children to hospital, while others felt bothered by the tasks CHWs asked them to complete, for example, building toilets. A few others felt they should be compensated (by the CHWs) for (giving out) their demographic information. 
Perceived benefits of compensation. Nearly all participants from the active FGD thought that they would be paid a salary at the time of their selection. The inactive CHWs had been informed that the work was voluntary (and as such planned to drop out at an opportune time). In both FGDs, participants agreed that they did not receive any material support from the community. However, participants from the active FGD said the community offered emotional support through the ideas they shared. They also mentioned the facility CHEWs involving them in outreach programmes for which they were given an allowance. They viewed this as recognition of their experience. The county government was also introducing a monthly allowance of 2000 shillings for which they were appreciative.

Targets and meetings conducted. Participants in the active FGD held mid-monthly meetings to review progress and make financial plans for their self-help goat-rearing project. The inactive group conducted village dialogues twice a month and attended meetings once a month until they dropped out because they expected support from Aga Khan University, which did not come through. Performance targets set were based on achievement of those set in the previous evaluation period, for example, the number of women they would like to have on family planning. They would then check their family planning cards the following month to find out if this was achieved. For the building of the toilets, a certain timeline would be set to complete the toilet, and this would be monitored monthly.

Another key activity was community dialogues where CHWs discuss their work, make plans and set targets together with community members. Usually, CHEWs were invited to attend. In addition, there were referral targets where sick people and those on follow-up, for example, for immunisations, were referred appropriately. The CHW would then confirm (from hospital records) whether those referred followed through. The inactive CHWs indicated that they stopped (attending) community dialogues and monthly meetings as they were expecting the Aga Khan MNM project team to be present, but they failed to turn up on several occasions.

Reasons for $\mathrm{CHW}$ remaining active or inactive. Active CHWs indicated that behaviour change, that is, where the community members adopt positive health behaviours, motivates them to carry on with their work; the inactive CHWs indicated that the incentives provided would motivate them to resume community work. Reasons given for inactivity were (1) lack of stipend given that the CHWs have families to provide for and (2) inactive CHWs indicated that increased workload due to absence or resignation of some of their colleagues (where they were required to cover their households).

Challenges encountered in working as a CHW. The participants mentioned working long hours to reach their target households. Initially working under Aga Khan University, they would visit only 20 houses per month. However, when the government revised this to 100 households per month, targets became unachievable. Lack of a stipend or salary meant that they had to work extra hard to provide for their families. In some instances, volunteering took a lot of additional (unpaid) time and they often worked throughout the day without lunch. Sometimes the households visited would be empty at the time, so they had to make several re-visits, often over a number of days. In some instances, the community members failed to meet their targets (eg, building toilets), and some of the community members refused to cooperate under the perception (from rumours) that they were (being) paid and were wasting their time. There was also negative community feedback due to unrealistic expectations, for example, CHWs were expected to provide treatment for minor ailments such as coughs and jigger infestations.

Suggestion for improving CHW work environment. Both groups felt that the provision of a means of transport such as motorcycles would make the work easier as many households would be covered over short periods and would (in emergency cases) provide ambulance services to the community. Receiving (monetary) incentives would reduce the anxiety of being unable to support their families. They also suggested that the number of households covered be reduced (back to 20). Tokens such as bags and Khangas should also be provided.

\section{DISCUSSION}

Numerous studies have demonstrated that CHWs can help reduce child morbidity and mortality in certain settings. ${ }^{4} 26$ 34-37 For example, a multicounty study by Celletti et al reported that access to quality HIV services can benefit from a task shifting approach employing CHWs. ${ }^{38}$ Task shifting has occurred in several settings, not only in HIV/AIDS, with variable success. Thus, it remains to be seen whether care by CHWs truly leads to better health outcomes. Trials to address this question are currently underway. ${ }^{39-41}$

The current study, conducted among a large cohort of CHWs, presents important findings. Half of the original cohort dropped out of the project over a 7-year period, and the researchers estimated incidence of attrition at 48 per 1000 trained CHWs per year. These are significant findings given that the CHWs were selected, trained and supported within an ongoing community health programme implemented by a local stakeholder (Aga Khan University). It is anticipated that attrition would be much higher in government programmes not supported by non-governmental partners. Indeed, an annual attrition of 20\% was observed in a neighbouring Sub-county where programme support from external partners was inconsistent (PHO, Mwanamwinga Division, Kaloleni Sub-county: personal communication).

In the multivariate analyses, a few key sociodemographic characteristics were associated with attrition. Compared with women, male CHWs were almost three times more likely to leave community health work. A number of reasons could explain this observation. First, 
the study community is mainly patriarchal and adult men are expected to provide for their families. Volunteering for community work may interfere with their private work and is thus not prioritised over gainful employment. Data from a similar area in the neighbouring county of Kilifi show a disproportionately lower proportion of male residents above 20 years of age, which is suggestive of labour outmigration. Another reason for this observation could be altruism. Studies from developed countries have shown that women may be more likely to give materially or volunteer their time than men. ${ }^{42}$ Even among unmarried young people, women are at least $18 \%$ more likely to volunteer for community service compared with men. ${ }^{43}$ In the context of developing countries, other gender-related factors may be at play. In these countries, access to employment opportunities does not favour women, particularly those with little or no formal education. Thus, even though these CHWs are volunteers, the small stipends provided for travel, training and meeting allowances can be important economic motivators for engaging in CHW work.

Our findings also showed that age was associated with attrition, with those below 40 years of age being more likely to leave CHW work relative to their older counterparts. In the context of a rural area such as the setting for our study, this is more likely related to labour and related (eg, educational) outmigration explained above. Volunteering for community service requires motivation that is beyond the concern for self or for immediate family and friends since the benefits extend to socially distant others in the larger community. ${ }^{44}$ Evidence suggests that this prosocial behaviour increases with age,${ }^{45}$ and that this age-related prosociality is not a function of social distance. ${ }^{46}$ A likely explanation for this observation is that younger people would be more preoccupied with fending for and raising young families. ${ }^{47}$ In the context of community health work, there are specific factors like among Ubuntu in South Africa where older CHWs may respect a 'shared African humanity' whereas younger workers may have more access to training and education. ${ }^{44}$

With regard to marital status, we found that compared with their married peers, postmarriage (separated/ divorced) CHWs were five times more likely to drop out of volunteer community health work. This is in agreement with other studies. ${ }^{28}{ }^{48}$ With no one to share other demands on their time such as employment, single and postmarriage parents may have less time and energy to devote to volunteering. ${ }^{47}$

Strong management of the CHW programmes such as providing refresher trainings and feedback on work done was associated with greater retention. To ensure that they contribute effectively to health programmes, CHWs need to be supported through human resource management practices, such as continuous skills and knowledge improvement through refresher training as well as regular performance appraisal and feedback. ${ }^{49}$ In fact, systems that 'listen' to CHWs and allow them to impact their own work conditions are thought to be the most effective. ${ }^{50}$ Due to competing responsibilities and weak management systems, these expectations are, however, not always met by their frontline supervisors, who in most instances include nurses working busy primary care facilities or volunteer CHC members. ${ }^{1751}$ Surprisingly, we found that increasing frequency of supervision was associated with higher odds of attrition. While this may be counterintuitive, it is likely that CHWs viewed increased supervision as intrusive, aimed at fault-finding rather than being supportive and generally not addressing real issues and challenges related to their work as was found in a study in Mozambique ${ }^{51}$ and may also be viewed as a sign of poor performance. ${ }^{52}$ Since the question only looked at the final month of work for the inactive CHWs, it is also likely that these CHWs were having performance issues, had almost stopped working and were more likely candidates for frequent visits from the supervisor to address performance problems or dissatisfaction. Relationship with peers was one of the strongest determinants of attrition in this cohort. Those who deemed that being in a peer organisation like CHW grouping was unimportant were five times more likely to drop out of the CHW programme. This finding is in congruence with findings from another study in Tanzania in which perceived good relations with coworkers contributed to high levels of satisfaction. ${ }^{53}$ In volunteer community health programmes with inadequate supervision due to low supervisor:CHW ratios, embedded peer support networks would be an invaluable resource in enhancing group integration and motivation and would more likely lead to improved performance and facilitate communication with health facilities and programme personnel. ${ }^{54}$

These findings must be placed in wider context. The government of Kenya has adopted the Community Health Strategy to work with CHWs as volunteers across the country. Any stakeholder (like the Aga Khan University in this instance) working with the community is expected to follow the guidelines of working with CHWs. ${ }^{30}$ The current study can give insights from both active and inactive CHWs from the quantitative and qualitative perspectives. Both groups expressed that they were willing to work for their community and viewed it as an important undertaking. Although there were divergent findings between quantitative results and FGD opinions about compensation, both groups recommended some form of monetary emolument to allay their anxieties about providing for their families while serving as CHWs. In past studies, the role of financial payments has been hotly debated. ${ }^{55}$

To date, there have been no rigorous studies such as randomised controlled trials examining the relationship between CHW payment and quality of care, retention and health outcomes. In a prior review, the combined effects of payment, training and motivation by community factors are discussed, ${ }^{56}$ but clearly more robust data are needed in this area. However, studies among health facility personnel have found a relationship between payment for performance and retention, ${ }^{57}$ but evidence 
on the effect of payment on improvement in quality of care $^{58}$ and provision of healthcare and health outcomes ${ }^{59}$ was inconclusive.

Along with evaluating the feasibility of payments in the form of salary in Kenya and other similar settings, there are several other CHW management strategies worth considering given our findings. Most CHWs, active or not, expressed the desire for adequate training. From the focus groups, it was clear that the CHWs lacked adequate health knowledge, which then subsequently influenced their practice. Perhaps the next most salient issue was the request for refresher trainings. These boosters were considered vital ways to retain health knowledge and to stay connected to and form a sense of community and support with fellow CHWs. Keeping allotments (number of households served by a CHW) reasonable may be another strategy. Over the course of this study, a new governmental policy was enacted wherein each CHWs was allotted 100 households. All CHWs expressed the need for downward revision, with each CHWs serving 20 households. Another key management strategy is being clear on expectations. Some of the CHWs who left did so because it was their understanding that they would receive token payments, they would receive transport in the form of motorcycles and they would eventually get a salary-none of which occurred.

CHWs who remained were often in the situation that they were appreciated and recognised by the community. This was one of the reasons they chose to volunteer. This is supported in the findings of other published data. However, the successful and sustainable deployment of CHWs is dependent on the existence of an enabling environment that includes a supportive regulatory framework, functioning referral systems, robust quality assurance mechanisms (such as standardised training and supportive supervision), basic monetary incentives to provide reasonable financial security and sufficient resources for health service delivery. Despite these perceptions, many CHW programmes have not been sustainable, and factors that motivate and improve their retention rates have not been described. The overall environment of international public health has changed dramatically with health sector reforms and decentralisation. Local governments have greater autonomy and authority to develop and finance health solutions appropriate to their locales. As these dramatic changes in the public health context create new opportunities for programmes that include CHWs, this is a critical time to review the past experience and draw lessons for the future.

\section{Study limitations}

This study was not part of the initial MNM project design and therefore no funding had been allocated for it. Due to resource constraints, we were unable to conduct more focus group discussions and hence the findings of the qualitative study may not be sufficiently robust. However, we attempted to ensure a balanced representation of villages in each group, and we are therefore reasonably confident that our sample was a fair representation of our study population. Also, since the study was conducted as part of a project in which the CHWs were involved, there is a possibility of desirability bias in the positive responses received, particularly among those who remained. However, we attempted to mitigate this by using interviewers who were external to the project.

\section{CONCLUSION}

This study estimates a high prevalence and incidence of CHW attrition in Kwale County, in rural Kenya and identifies some of the individual-level CHW characteristics and CHW programme management factors that influence attrition from community health programmes. That demographic factors are significant determinants of CHW attrition should be an important consideration in the policy discourse on sustainability of CHW-led programmes, for instance, exploring the potential for CHW work as a sustainable career option, which is attractive across different age groups and gender. Community health programme managers should consider regular refresher training, performance monitoring and feedback as well as adopting innovative strategies to enhance peer support among CHWs as potential incentives for CHW retention in similar rural lower middle-income country contexts. The design of community health programmes should incorporate basic monetary incentives to supplement the CHW incomes and allay anxieties about their ability to fend for their families while performing CHW roles, include consultations on the size of the workload and ensure effective communication on the expectations for and from each partner.

Acknowledgements We would like to thank the County Health Director of Kwale County, Dr Hajara El-Busaidy, and the Msambweni Sub-county Medical Officer of Health, Dr Aggrey Okumu, for supporting this study, the community health workers for participating in the study and the local Sub-county government administration teams for facilitating this work in the community. We are grateful to Sophie Chabeda for helping with the qualitative analyses.

Contributors AKN, LWN and KMM were involved in the conception and design of the study. Field work was supervised by FA, MH and LWN, supported by AL and GL. Quantitative analyses were conducted by AKN with support from KMM and qualitative analyses by Sophie Chabeda with support from LWN. AKN wrote the first draft of manuscript with review and additions by KMM and LWN. All authors contributed to interpretation of findings, reviewing, revising and approving the final manuscript.

Funding This study was conducted under the Mama Na Mtoto II (MNM II) project funded by the Delegation of the European Commission in Kenya (contract no. DCI-NSAPVD/2011/276-298) and the Aga Khan Foundation, UK.

Disclaimer The funders played no role in the design of the study, in collection, analysis and interpretation of data or in preparation of this manuscript.

Competing interests None declared.

Patient consent Obtained.

Ethics approval Aga Khan University (East Africa) Research Ethics Committee.

Provenance and peer review Not commissioned; externally peer reviewed.

Data sharing statement No additional data are available.

Open access This is an open access article distributed in accordance with the Creative Commons Attribution Non Commercial (CC BY-NC 4.0) license, which permits others to distribute, remix, adapt, build upon this work non-commercially, 
and license their derivative works on different terms, provided the original work is properly cited, appropriate credit is given, any changes made indicated, and the use is non-commercial. See: http://creativecommons.org/licenses/by-nc/4.0/.

\section{REFERENCES}

1. World Health Organization. Community Health Workers: what do we know about them? The state of the evidence on programmes, activities, costs and impact on health outcomes of using community health workers. Geneva: World Health Organization, 2007.

2. World Health Organization. Global strategy on human resources for health: Workforce 2030. Geneva: World Health Organization 2016.

3. Brunie A, Wamala-Mucheri P, Otterness C, et al. Keeping community health workers in Uganda motivated: key challenges, facilitators, and preferred program inputs. Glob Health Sci Pract 2014;2:103-16.

4. Perry HB, Zulliger R, Rogers MM. Community health workers in low-, middle-, and high-income countries: an overview of their history, recent evolution, and current effectiveness. Annu Rev Public Health 2014;35:399-421.

5. Gilmore B, McAuliffe E. Effectiveness of community health workers delivering preventive interventions for maternal and child health in low- and middle-income countries: a systematic review. BMC Public Health 2013;13:847

6. Glenton C, Scheel IB, Pradhan S, et al. The female community health volunteer programme in Nepal: decision makers' perceptions of volunteerism, payment and other incentives. Soc Sci Med 2010;70:1920-7.

7. Lassi ZS, Bhutta ZA. Community-based intervention packages for reducing maternal and neonatal morbidity and mortality and improving neonatal outcomes. Cochrane Database Syst Rev 2015;3:CD007754.

8. Lassi ZS, Kumar R, Bhutta ZA, et a/Community-based care to improve maternal, newborn, and child health. In: Black RE, Laxminarayan R, Temmerman M, eds. . Reproductive, maternal, newborn, and child health: disease control priorities. Third edition. Washington (DC);2016.2.

9. CDI Study Group. Community-directed interventions for priority health problems in Africa: results of a multicountry study. Bull World Health Organ 2010;88:509-18.

10. Wringe A, Cataldo F, Stevenson N, et al. Delivering comprehensive home-based care programmes for HIV: a review of lessons learned and challenges ahead in the era of antiretroviral therapy. Health Policy Plan 2010;25:352-62.

11. Brownstein JN, Chowdhury FM, Norris SL, et al. Effectiveness of community health workers in the care of people with hypertension. Am J Prev Med 2007;32:435-47.

12. Wennerstrom A, Vannoy SD, Allen CE, et alCommunity-based participatory development of a community health worker mental health outreach role to extend collaborative care in post-Katrina New Orleans. Ethn Dis 2011;21-S1-45.

13. van Ginneken N, Tharyan P, Lewin S, et al. Non-specialist health worker interventions for the care of mental, neurological and substance-abuse disorders in low- and middle-income countries. Cochrane Database Syst Rev 2013;11:CD009149.

14. Raphael JL, Rueda A, Lion KC, et al. The role of lay health workers in pediatric chronic disease: a systematic review. Acad Pediatr 2013;13:408-20.

15. Schneider H, Hlophe H, van Rensburg D. Community health workers and the response to HIV/AIDS in South Africa: tensions and prospects. Health Policy Plan 2008;23:179-87.

16. Keats EC, Ngugi A, Macharia W, et al. Progress and priorities for reproductive, maternal, newborn, and child health in Kenya: a Countdown to 2015 country case study. Lancet Glob Health 2017;5:e782-e795.

17. Ministry of Health. Taking the Kenya Essential Package for Health to the community: a strategy for the delivery of level one services. Nairobi: Ministry of Health, 2006.

18. Rachlis B, Sodhi S, Burciul B, et al. A taxonomy for communitybased care programs focused on HIV/AIDS prevention, treatment, and care in resource-poor settings. Glob Health Action 2013;6:20548

19. Sander LD, Holtzman D, Pauly M, et al. Time savings-realized and potential-and fair compensation for community health workers in Kenyan health facilities: a mixed-methods approach. Hum Resour Health 2015;13:6.

20. Henry JV, Winters N, Lakati A, et al. Enhancing the supervision of community health workers with WhatsApp mobile messaging: qualitative findings from 2 low-resource settings in Kenya. Glob Health Sci Pract 2016;4:311-25. -
21. Maes K, Kalofonos I. Becoming and remaining community health workers: perspectives from Ethiopia and Mozambique. Soc Sci Med 2013;87:52-9.

22. Bhattacharyya K, Winch P, LeBan KTM. Community health worker incentives and disincentives: how they affect motivation, retention, and sustainability. Arlington, Virginia, USA: USAID, 2001.

23. Nkonki L, Cliff J, Sanders D. Lay health worker attrition: important but often ignored. Bull World Health Organ 2011;89:919-23.

24. Mays DC, O'Neil EJ, Mworozi EA, et al. Supporting and retaining Village Health Teams: an assessment of a community health worker program in two Ugandan districts. Int J Equity Health 2017;16:129.

25. World Health Organization and Global Health Workforce Alliance Synthesis paper of the thematic working groups. Health work force 2030 - towards a global strategy on human resources for health. 2015.

26. Mwai GW, Mburu G, Torpey K, et al. Role and outcomes of community health workers in HIV care in sub-Saharan Africa: a systematic review. J Int AIDS Soc 2013;16:18586.

27. de Vries DH, Pool R. The influence of community health resources on effectiveness and sustainability of community and lay health worker programs in lower-income countries: a systematic review. PLoS One 2017;12:e0170217.

28. Ludwick T, Brenner JL, Kyomuhangi T, et al. Poor retention does not have to be the rule: retention of volunteer community health workers in Uganda. Health Policy Plan 2014;29:388-95.

29. Ministry of Health,. Linking Communities with the Health System: The Kenya Essential Package for Health at Level 1. A Manual for Training Community Health Workers. Nairobi, 2007.

30. Aga Khan University. Mama Na Mtoto. http://www.akdn.org/project/ mama-na-mtoto

31. Gitimu A, Herr C, Oruko H, et al. Determinants of use of skilled birth attendant at delivery in Makueni, Kenya: a cross sectional study. BMC Pregnancy Childbirth 2015;15:9.

32. Kitui JE, Dutton V, Bester D, et al. Traditional Birth Attendant reorientation and Motherpacks incentive's effect on health facility delivery uptake in Narok County, Kenya: an impact analysis. BMC Pregnancy Childbirth 2017;17:125.

33. Shipton L, Zahidie A, Rabbani F. Motivating and demotivating factors for community health workers engaged in maternal, newborn and child health programs in low and middle-income countries: a systematic review. J Coll Physicians Surg Pak 2017;27:157-65.

34. Amouzou A, Banda B, Kachaka W, et al. Monitoring child mortality through community health worker reporting of births and deaths in Malawi: validation against a household mortality survey. PLoS One 2014;9:e88939.

35. Bagonza J, Kibira SP, Rutebemberwa E. Performance of community health workers managing malaria, pneumonia and diarrhoea under the community case management programme in central Uganda: a cross sectional study. Malar J 2014;13:367.

36. Brenner JL, Kabakyenga J, Kyomuhangi T, et al. Can volunteer community health workers decrease child morbidity and mortality in southwestern Uganda? An impact evaluation. PLoS One 2011;6:e27997

37. Mkumbo E, Hanson C, Penfold S, et al. Innovation in supervision and support of community health workers for better newborn survival in southern Tanzania. Int Health 2014;6:339-41.

38. Celletti F, Wright A, Palen J, et al. Can the deployment of community health workers for the delivery of HIV services represent an effective and sustainable response to health workforce shortages? Results of a multicountry study. AIDS 2010;24 Suppl 1:S45-S57

39. Sando D, Geldsetzer P, Magesa L, et al. Evaluation of a community health worker intervention and the World Health Organization's Option B versus Option A to improve antenatal care and PMTCT outcomes in Dar es Salaam, Tanzania: study protocol for a clusterrandomized controlled health systems implementation trial. Trials 2014;15:359.

40. Geldsetzer P, Francis JM, Ulenga N, et al. The impact of community health worker-led home delivery of antiretroviral therapy on virological suppression: a non-inferiority cluster-randomized health systems trial in Dar es Salaam, Tanzania. BMC Health Serv Res 2017;17:160.

41. Nance N, Pendo P, Masanja J, et al. Short-term effectiveness of a community health worker intervention for HIV-infected pregnant women in Tanzania to improve treatment adherence and retention in care: a cluster-randomized trial. PLoS One 2017:12:e0181919.

42. Simmons WO, Emanuele R. Male-female giving differentials: are women more altruistic? J Econ Stud 2007;34:534-50.

43. Mesch DJ, Rooney PM, Steinberg KS, et al. The effects of race, gender, and marital status on giving and volunteering in Indiana. Nonprofit Volunt Sect Q 2006;35:565-87. 
44. Swartz A, Legacy SA. Legacy, legitimacy, and possibility: an exploration of community health worker experience across the generations in Khayelitsha, South Africa. Med Anthropol Q 2013;27:139-54.

45. Matsumoto Y, Yamagishi T, Li Y, Kiyonari T, et al. Prosocial behavior increases with age across five economic games. PLoS One 2016;11:e0158671.

46. Pornpattananangkul N, Chowdhury A, Feng L, et al. Social discounting in the elderly: senior citizens are good samaritans to strangers. J Gerontol B Psychol Sci Soc Sci 2017.

47. Selbee LK, Reed PB. Patterns of Volunteering Over the Life Cycle: Statistics Canada, 2000

48. Haile F, Yemane D, Gebreslassie A. Assessment of non-financial incentives for volunteer community health workers - the case of Wukro district, Tigray, Ethiopia. Hum Resour Health 2014;12:54.

49. Raven J, Akweongo P, Baba A, et al. Using a human resource management approach to support community health workers: experiences from five African countries. Hum Resour Health 2015;13:45.

50. Oliver M, Geniets A, Winters N, et al. What do community health workers have to say about their work, and how can this inform improved programme design? A case study with $\mathrm{CHWs}$ within Kenya. Glob Health Action 2015;8:27168.

51. Ndima SD, Sidat M, Give C, et al. Supervision of community health workers in Mozambique: a qualitative study of factors influencing motivation and programme implementation. Hum Resour Health 2015;13:63.
52. Greenspan JA, McMahon SA, Chebet JJ, et al. Sources of community health worker motivation: a qualitative study in Morogoro Region, Tanzania. Hum Resour Health 2013;11:52.

53. Mpembeni RN, Bhatnagar A, LeFevre A, et al. Motivation and satisfaction among community health workers in Morogoro Region, Tanzania: nuanced needs and varied ambitions. Hum Resour Health 2015;13:44

54. Lovell CC, Nduwayo H. Where There Are No Supervisors: Community Health Worker Peer Support Groups Huffington Post: USAID's Flagship Maternal And Child Survival Program. 2017 https://www.huffingtonpost.com/entry/58dbc33de4b07f61a2bb8a4c (accessed 7 May 2018).

55. Chandler $\mathrm{Cl}$, Chonya S, Mtei F, et al. Motivation, money and respect: a mixed-method study of Tanzanian non-physician clinicians. Soc Sci Med 2009;68:2078-88.

56. Singh D, Negin J, Otim M, et al. The effect of payment and incentives on motivation and focus of community health workers: five case studies from low- and middle-income countries. Hum Resour Health 2015;13:58.

57. Shen GC, Nguyen HT, Das A, et al. Incentives to change: effects of performance-based financing on health workers in Zambia. Hum Resour Health 2017;15:20.

58. Scott A, Sivey P, Ait Ouakrim D, et al. The effect of financial incentives on the quality of health care provided by primary care physicians. Cochrane Database Syst Rev 2011;9:CD008451.

59. Witter S, Fretheim A, Kessy FL, et al. Paying for performance to improve the delivery of health interventions in low- and middleincome countries. Cochrane Database Syst Rev 2012;2:CD007899. 